\title{
Airway management in a case of Treacher Collins Syndrome-A case report
}

\author{
Dr Rashmi.H.D ${ }^{1}$, Dr Manjula.R ${ }^{2}$, Dr Meera.Balasubramanyam ${ }^{3}$, Dr Varsha ${ }^{4}$, \\ Dr Aditi ${ }^{5}$ \\ (Assistant professor ${ }^{1}$, Associate professor ${ }^{2}$, Professor $^{3}$, Post graduate $^{4}$, Post graduate ${ }^{5}$, Department of \\ anaesthesiology, Adichunchanagiri institute of medical sciences, Karnataka,India)
}

\begin{abstract}
Treacher Collins Syndrome, also known as mandibulofacial dysostosis is a rare autosomal dominant disorder characterized by craniofacial abnormalities and dysmorphic facies. The estimated incidence varies about 1 in 40,000 to 1 in 70,000 live births. It is associated with difficult mask ventilation and intubation because of facial abnormalities. Hence, recognition of this syndrome is of prime importance for us as anaesthesiologists to prevent potential airway problems under anaesthesia. Here, we report a case of Treacher Collins Syndrome posted for pseudopterygium excision, who was successfully managed with general anaesthesia.
\end{abstract}

Keywords: Treacher Collins Syndrome; Micrognathia; General anaesthesia; difficult airway.

\section{Introduction}

Treacher Collins syndrome,also known as mandibulofacial dysostosis, is a rare autosomal dominant congenital anomaly, which was first described by Edward Treacher Collins, a British ophthalmologist, in $1900^{1}$.

The classical features of this syndrome include downward-slanting eyes, colobomata of lower eyelids, strabismus, hypoplasia of facial bones mainly mandibular and zygomatic bones leading to micrognathia and malocclusion,dental anomalies, malformation of the auricle with atresia of the external auditory canals, maldevelopment of the middle-ear ossicles, associated conductive hearing loss and cleft lip and cleft palate. ${ }^{2}$ Sometimes it is also associated with obstructive sleep apnoea ${ }^{3}$

We report a case of a 7 year old boy, with Treacher Collins Syndrome with pseudopterygium in right eye, posted for pterygium excision who presented to us with micrognathia, high arched palate, repaired cleft lip and palate,managed with general anaesthesia.

\section{Case Summary}

A 7year old male child, weighing $16 \mathrm{kgs}$, with Treacher Collins syndrome, was posted for the excision of pseudopterygium in the right eye. Pre anaesthetic evaluation was done in detail. His mother was the Informant. There was a history of grade 11 consanguinous marriage in the parents. Previously the child was operated for cleft lip and cleft palate under general anaesthesia at the age of 6 months and 6 years respectivelythe perioperative period being uneventful.There was a history of speech difficulty,hard of hearing and recurrent respiratory tract infections since childhood. There was no history of sleep apnea,loud nocturnal snoring and frequent arousals during sleep. The younger sibling also had similar features.

On examination, the child had dysmorphic facial features.He had microcephaly, low set ears, depressed nasal bridge, micrognathia, high arched palate, malaligned teeth with epulis in place of the upper central incisors, operated scar of cleft lip repair, and low hair line. He also had hypertelorism with pseudopterygium in the right eye.Airway examination revealed mallampatti grade 2, adequate neck extension and mouth opening.His vitals were stable, and systemic examination revealed a systolic murmur in the mitral and tricuspid areas.

The laboratory reports concurred with the clinical findings, with a hemoglobin percentage of $10.2 \mathrm{gm} \%$. 2D-echocardiography showed normal cardiac chambers, mild mitral regurgitation and mild tricuspid regurgitation, no regional wall motion abnormality with good biventricular function. Ultrasound abdomen revealed mild hepatosplenomegaly with altered liver echotexture. Other laboratory parameters were within normal limits. 


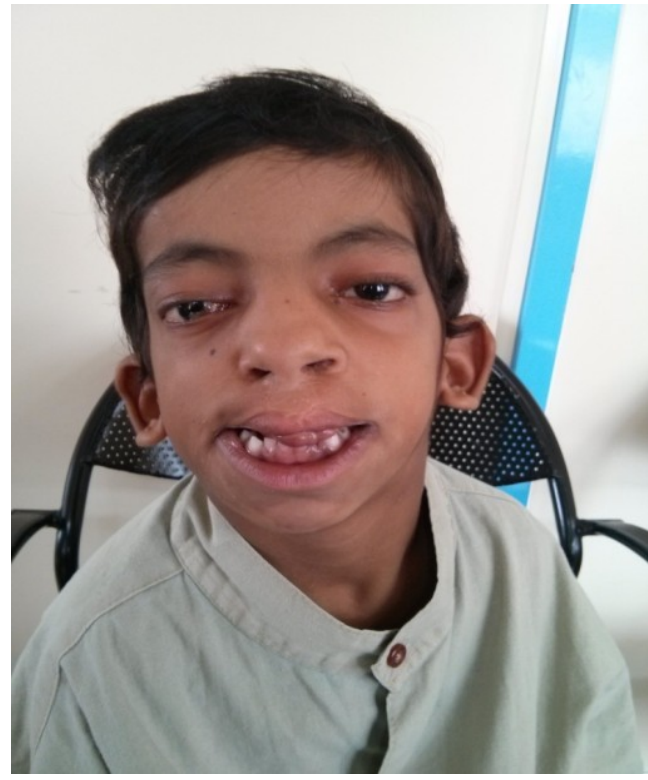

Fig:1 Front view of Treacher Collins syndrome patient showing downslanting of palpebral fissures, hypertelorism,operated scar of cleft lip,malocclusion of teeth and epulis

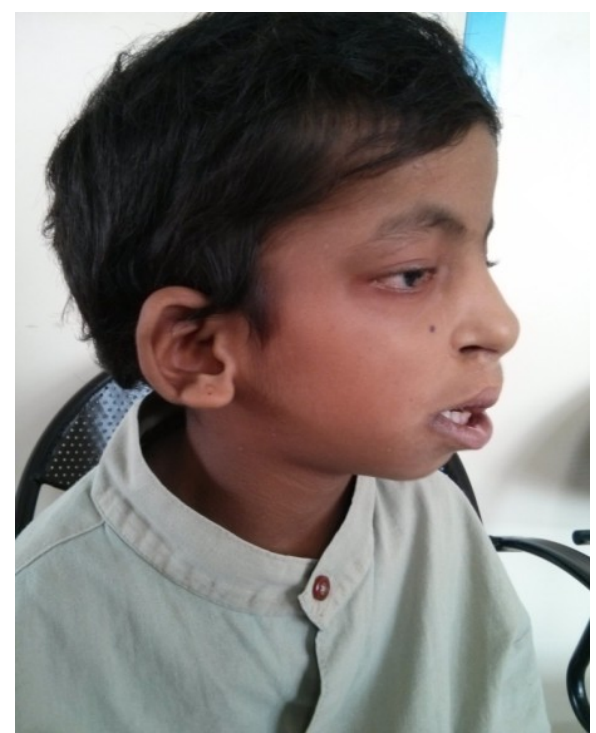

Fig:2 Side view of Treacher Collins syndrome patient showing deformed ear auricles,micrognathia

Anticipating difficult airway, difficult airway cart was kept ready which consisted of, two working scopes with both Macintosh and Miller blades, cuffed and uncuffed endotracheal tubes of size 4, 4.5, 5 and 5.5, paediatric Laryngeal mask airways(LMA), proper fitting masks and Jackson Rees (JR) circuit, pediatric size stylet . Flexible fibreoptic laryngoscope was also kept ready. All emergency drugs were kept ready and arrangements were also made for emergency tracheostomy.

Our anaesthetic plan was General anaesthesia with endotracheal intubation by inhalational induction using sevoflurane, with the intention of keeping spontaneous respiration intact. We didn't opt for awake intubation as age was the limitation. Accordingly, child was shifted to the operation theatre with a $22 \mathrm{~g}$ intravenous( iv) cannula in the dorsum of left hand and Isolyte P was started. Monitors were connected and baseline values of pulse rate, blood pressure and room air saturation were noted. Child was preoxygenated with $100 \%$ oxygen for 5 minutes, and premedicated with inj.atropine $0.3 \mathrm{mg}$ iv. Child was induced with incremental doses of sevoflurane. After required depth of anaesthesia was obtained, laryngoscopy and intubation was attempted twice unsuccessfully by a second year postgraduate.As only epiglottis could be seen and as mask ventilation was adequate, inj. Propofol 30mg iv and inj.succinylcoline-30 mg iv was given. Laryngoscopy and intubation was attempted again by a senior anaesthesiologist, and trachea was successfully intubated with size 5 $\mathrm{mm}$ uncuffed styletted endotracheal tube.Bilateral equal air entry was confirmed and tube was fixed. Anaesthesia was maintained with oxygen + nitrous oxide + sevoflurane $1 \%+$ inj atracurium $2.5 \mathrm{mg}$ iv in 
incremental doses. The child was haemodynamically stable throughout the procedure,which lasted for two and a half hours. At the end of surgical procedure, the child was reversed with inj. Neostigmine $0.8 \mathrm{mg}$ iv and inj. Glycopyrrolate $0.2 \mathrm{mg}$ iv and gentle oral suctioning was done. Child was successfully extubated and shifted to the post anaesthetic care unit, for further observation.In the post operative period, the child was monitored for 48 hours, which was uneventful.

\section{Discussion}

Treacher Collins Syndrome is a rare autosomal dominant congenital disorder. It is also called Treacher Collins Franceschetti Syndrome or mandibulofacial dysostosis. It is mainly characterized by craniofacial deformities like mandibular and zygomatic hypoplasia. TCOF1 gene mutations are the most common cause of the disorder ${ }^{2}$

The phenotypical features of Treacher Collins Syndrome probably result from the bilateral congenital malformations involving first and second branchial arches $\mathrm{s}^{4,5}$.

Classical clinical features of this syndrome:

\begin{tabular}{|c|c|c|c|}
\hline Eyes & Ears & Facial bones & Others \\
\hline $\begin{array}{l}\text {-Anti mongoloid slant of } \\
\text { palpebral fissures }\end{array}$ & $\begin{array}{llll}\text {-Small, } & \text { rotated } & \text { or } & \text { absent } \\
\text { auricles } & & & \\
\end{array}$ & $\begin{array}{l}\text {-Maxillary and mandibular } \\
\text { hypoplasia }\end{array}$ & $\begin{array}{l}\text {-Cleft lip and cleft } \\
\text { palate }\end{array}$ \\
\hline $\begin{array}{l}\text { - Colobomata of the lower } \\
\text { eyelids }\end{array}$ & $\begin{array}{l}\text {-Atresia of external auditory } \\
\text { canals }\end{array}$ & -Micrognathia & -Speech difficulties \\
\hline -Strabismus & $\begin{array}{l}\text { Dysmorphic ossicles of middle } \\
\text { ear cavity }\end{array}$ & - Nasal deformity & $\begin{array}{l}\cdot \text { Obstructive } \\
\text { apnoea }\end{array}$ \\
\hline -Refractive errors & -Conductive hearing loss & -High arched palate & \\
\hline & & •Malocclusion & \\
\hline
\end{tabular}

Table: 1 Clinical features of Treacher Collins Syndrome

Necita L.Roa et $\mathrm{al}^{3}$ has reported a case of 15 year old female patient with Treacher Collins syndrome with obstructive sleep apnea and seizure disorder who was posted for bilateral mandibular osteotomies.Blind nasotracheal intubation was tried after anaesthetizing the airway, but they were unsuccessful.Then they successfully intubated using thiopental and d-tubocurarine. She was extubated on 3rd postoperative day.

Garry et al ${ }^{6}$ has reported a case of 4 year old boy with treacher Collins syndrome posted for canaloplasty.They tried conventional method of intubation and laryngoscopy without giving muscle relaxants using macintosh and miller blades several times. They were unsuccessful and their laryngoscopy was obstructing the upper airway.Then ,they successfully intubated by doing blind nasotracheal intubation. Intraoperative and postoperative course was normal.

LMA ${ }^{7,8}$ has also been tried for these patients .Lisa Muraika et al ${ }^{7}$ have used a novel method of Fiberoptic tracheal intubation through a LMA in a Child with Treacher Collins Syndrome Initially they tried direct laryngoscopy with both the Macintosh and Miller blades which failed to reveal the vocal cords by using sevoflurane induction with rocuronium. Then they went for this newer approach.

$\mathrm{S}$ Agrawal et $\mathrm{al}^{9}$ have tried yet another technique called as Paraglossal straight blade intubation technique for intubating a child of Treacher Collins Syndrome.

In our case,we tried conventional laryngoscopy with macintosh blade using inhalational induction in the beginning as done by Lisa Muraika et al ${ }^{7}$ and Leena Goel et $\mathrm{al}^{10}$. As we were unsuccessful,and after confirming adequacy of mask ventilation, we intubated the patient with the aid of propofol and succinylcholine.

\section{Conclusion}

Treacher Collins Syndrome presents with the primary concern of airway management for the anaesthesiologist. As there is mandibular hypoplasia leading to micrognathia, high arched palate, cleft lip and cleft palate, there is always an expected risk of difficult intubation.Difficult airway cart with all different gadgets for securing the airway should be kept ready. All the emergency drugs like adrenaline,ionotropes and steroids should also be kept within reach to tide over untoward complications of hemodynamic instability, laryngospasm or bronchospasm and aspiration

\section{References}

[1] Dean L. Mittman, MD, and Orlando G. Rodman, MD Detroit ,Michigan. Mandibulofacial dysostosis (treacher collins syndrome):a case report. Journal of the national medical association;vol. 84(12), 1992,1051-1054.

[2] Sowmya B Shetty, Ann Thomas, Raghavendra Pidamale. Treacher Collins syndrome : A case report and a brief review on diagnostic aids. International Journal Of Clinical Pediatric Dentistry, 4(3), 2011,235-239

[3] Necita L. Roa, MD and Kenneth S. Moss, MD. Treacher Collins syndrome and sleep apnoea: Anesthetic considerations. Anesthesiology, 60(1),1984, 71-73, 
[4] Abengochea Cotaina A, Sanmiguel Gilg,Vila Sanchez M,Martinez Trens M,Baena Montilla P.Anaesthesia in a patient with Treacher Collins syndrome. Rev Esp Anesthesiol Reanim.;37(2),1990, 95-97

[5] Fahim Ahmed Shah,Ramakrishna.S,Ingle Vijendra,Dada J E,Khabori Mazin A1, Murty PSN. Treacher Collins Syndrome with acute airway obstruction. International journal of pediatric otorhinolaryngology. 54, 2000, 41-43.

[6] Garry S. Sklar, M.D and Benton D. King, M.D. Endotracheal intubation and Treacher Collins syndrome. Anesthesiology; 44( 3), March 1976

[7] Lisa Muraika, DO, Julius S. Heyman, MD, PhD, and Yuri Shevchenko, MD. Fibreoptic tracheal intubation through a laryngeal mask airway in a child with Treacher Collins syndrome. Anesth Analg, 97,2003,1298-9

[8] Toshiya Ebata MD, Shunichi Nishiki MD, Akio Masuda MD, Keisuke Amaha MD. Anaesthesia for Treacher Collins syndrome using a laryngeal mask airway. Can J Anaesth, 38,1991,1043-5

[9] S Agrawal, V Asthana, J Sharma, U Sharma, R Meher. Alternative Intubation Technique In A Case Of Treacher Collins Syndrome. The Internet Journal of Anesthesiology. 11(1),2005.

[10] Leena Goel, Santosh kumar Bennur, Shweta Jambhale. Treacher Collins syndrome- A challenge for anaesthesiologist. Indian Journal of Anaesthesia; 53 (4), 496-500 